\title{
PI3K/mTOR inhibition potentiates and extends palbociclib activity in anaplastic thyroid cancer
}

\author{
Kristen Wong, Francesca Di Cristofano, Michela Ranieri, Daniela De Martino and Antonio Di Cristofano \\ Department of Developmental and Molecular Biology, Albert Einstein College of Medicine, Bronx, New York, USA \\ Correspondence should be addressed to A Di Cristofano: antonio.dicristofano@einstein.yu.edu
}

\begin{abstract}
Anaplastic thyroid carcinoma (ATC) is the most aggressive form of thyroid cancer. Despite its low incidence, it accounts for a disproportionate number of thyroid cancer-related deaths, because of its resistance to current therapeutic approaches. Novel actionable targets are urgently needed to prolong patient survival and increase their quality of life. Loss and mutation of the RB1 tumor suppressor are rare events in ATC, which suggests that therapies directed at inhibiting the cyclin D/CDK4 complexes, responsible for RB phosphorylation and inactivation, might be effective in this tumor type. In fact, we found that the CDK4/6 inhibitor, palbociclib, strongly inhibits proliferation in all the RB1 wild-type ATC cell lines tested. Efficacy was also observed in vivo, in a xenograft model. However, ATC cells rapidly developed resistance to palbociclib. Resistance was associated with increased levels of cyclin D1 and D3. To counter cyclin D overexpression, we tested the effect of combining palbociclib with the PI3K/mTOR dual inhibitor, omipalisib. Combined treatment synergistically reduced cell proliferation, even in cell lines that do not carry PI3K-activating mutations. More importantly, low-dose combination was dramatically effective in inhibiting tumor growth in a xenograft model. Thus, combined $\mathrm{PI3K} / \mathrm{mTOR}$ and CDK4/6 inhibition is a highly promising novel approach for the treatment of aggressive, therapy-resistant thyroid cancer.
\end{abstract}

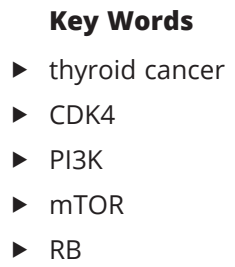

Endocrine-Related Cancer (2019) 26, 425-436

\section{Introduction}

Anaplastic thyroid carcinoma (ATC) is the most aggressive thyroid cancer subtype, with a median overall survival of less than 9 months when patients are treated with multimodal therapy and less than 3 months with palliative care (Prasongsook et al. 2017). ATC usually presents at diagnosis with local invasion and distant metastasis (Patel \& Shaha 2006, Smallridge 2012). Cytotoxic chemotherapy and radiation therapy are generally not very effective in prolonging survival of ATC patients (Ain et al. 2000, Higashiyama et al. 2010, Sherman et al. 2011). As such, ATC remains one of the most lethal tumors.

The recent approval of a combination therapy with the BRAF inhibitor dabrafenib and the MEK inhibitor trametinib for patients with unresectable or metastatic $B R A F^{V 600 E}$-positive ATC (Saini et al. 2018) has generated enthusiasm in the field, but it is projected to benefit less than $50 \%$ of ATC patients, underlining the need for additional rationally designed approaches. The growing availability of targeted kinase inhibitors and immunomodulatory molecules, together with easier access to detailed tumor molecular characterization, have fostered the development and testing of combinatorial approaches that in several cases have shown promising results (Subbiah et al. 2018, Iyer et al. 2018a,b).

Dysregulation of cell cycle control is one of the main hallmarks of cancer. Upon mitogenic stimulation, 
in normal cells, transition from the G0/G1 phases of the cell cycle into the $S$ phase is controlled by complexes formed by D-type cyclins and the CDK4 and CDK6 kinases, which phosphorylate and inactivate the RB tumor suppressor. In turn, RB inactivation releases the E2F transcription factors to promote entry into $S$ phase (Sherr 2000). Tumor cells bypass the G1 checkpoint through different mechanisms, including increased cyclin D expression, loss of CDK inhibitors, increased CDK4 and -6 expression, or RB1 inactivation (Sherr 2000).

Inhibition of the CDK4/6 kinases has recently become an FDA-approved treatment for advanced ER+ breast cancer, underlining the power of therapeutic approaches directed at restoring proper cell cycle control (Walker et al. 2016). At the same time, it has become clear that CDK $4 / 6$ inhibitor therapy is rapidly countered by the development of resistance (O'Leary et al. 2018).

The prime determinant of CDK4/6 inhibitor's efficacy is the presence of functional $\mathrm{RB}$ in the tumor cells. Based on the notion that $R B 1$ is not frequently mutated in ATC, we have explored the feasibility and efficacy of CDK4/6 inhibition in ATC.

\section{Materials and methods}

\section{Cell lines}

All cell lines used in this study were maintained at $37^{\circ} \mathrm{C}$ with $5 \% \mathrm{CO} 2$ in the culture media indicated in Table 1. Mouse cell lines were established from ATCs developed by genetically engineered mice (Antico Arciuch et al. 2011, Dima et al. 2011). Cell line identity was validated by STS profiling as well as by amplifying and sequencing genomic fragments encompassing their known mutations.

\section{Drug treatments and cell proliferation assay}

The CDK4/6 inhibitor palbociclib was provided by Pfizer and prepared in $50 \mathrm{mM}$ lactate. The PI3K/mTOR inhibitor, omipalisib, and the MEK inhibitor, trametinib, were purchased from Selleck Chemicals (Houston, TX, USA) and dissolved in DMSO. For drug sensitivity experiments all the inhibitors were added $12 \mathrm{~h}$ after plating cells in 12-well plates. Three days after treatment, cells were trypsinized and counted using a Z2 Coulter particle counter (Beckman Coulter). Statistical analysis and EC50 value calculation were obtained using GraphPad Prism (GraphPad Software).

(c) 2019 Society for Endocrinology Published by Bioscientifica Ltd. Printed in Great Britain
For long-term proliferation, $5 \times 10^{4}$ cells were plated in presence of DMSO or palbociclib $\left(\mathrm{EC}_{90}\right)$. Every 3 days, cells were harvested, counted and $5 \times 10^{4}$ cells were reseeded.

Statistical analysis of drug synergy was done using the Chou-Talalay method (Chou \& Talalay 1984) and the Calcusyn Software (Biosoft, Cambridge, UK). To determine synergy between two drugs, the software uses a medianeffect method that determines if the drug combination produces greater effects together than expected from the summation of their individual effects. The combination index (CI) values are calculated for the different doseeffect plots (for each of the serial dilutions) based on the parameters derived from the median-effect plots of the individual drugs or drug combinations at fixed ratios. The CI was calculated based on the assumption of mutually nonexclusive drug interactions. CI values significantly $>1$ are antagonistic, not significantly different than 1 are additive and values $<1$ are synergistic.

\section{Western blot analysis}

Cells were homogenized on ice in radioimmunoprecipitation assay (RIPA) buffer supplemented with Halt Protease and Phosphatase Inhibitor cocktail (Thermo Fisher Scientific) and centrifuged to remove debris. Protein concentration was determined using the Pierce BCA protein kit (Thermo Fisher Scientific). Western blot analysis was conducted using $50 \mu \mathrm{g}$ of proteins on ExpressPlus precast gels (Genescript, Piscataway, NJ, USA). Proteins were blotted onto polyvinylidene difluoride membranes (EMD Millipore). The membranes were probed with the indicated antibodies (RB \#9313, pRB \#3590, cyclin D1 \#2978, ciclin D3 \#2936, cyclin E1 \#20808, pAKT \#4060, AKT \#4685, Actin \#3700, Tubulin \#2146, all from Cell Signaling). All the primary antibodies were used at a dilution of 1:1000 in 5\% BSA in TBS-T. Signals were detected with HRP-conjugated secondary antibodies (Thermo Fisher Scientific) and the chemiluminescence substrate Luminata Crescendo (EMD Millipore).

\section{RNA extraction and real-time PCR}

Total RNA was extracted with TRIzol reagent (Invitrogen) according to the manufacturer's protocol. RNA yields were assessed using a NanoDrop 1000 (Thermo Fisher Scientific). About $1 \mu \mathrm{g}$ of RNA was reverse transcribed using the Maxima first strand cDNA synthesis kit (Thermo Fisher Scientific) according to the manufacturer's instructions. Quantitative real-time PCR 
Table 1 Cell lines used in this study.

\begin{tabular}{|c|c|}
\hline Cell line & Species of origin \\
\hline T4888M & Mouse \\
\hline T3533 & Mouse \\
\hline T1860 & Mouse \\
\hline T1903 & Mouse \\
\hline A274 & Mouse \\
\hline A275 & Mouse \\
\hline T7152 & Mouse \\
\hline T7189 & Mouse \\
\hline THJ16T & Human \\
\hline CAL62 & Human \\
\hline C643 & Human \\
\hline OCUT2 & Human \\
\hline T238 & Human \\
\hline $8505 c$ & Human \\
\hline SW1736 & Human \\
\hline THJ21T & Human \\
\hline $\mathrm{T} 243$ & Human \\
\hline T235 & Human \\
\hline HTH104 & Human \\
\hline ACT1 & Human \\
\hline
\end{tabular}

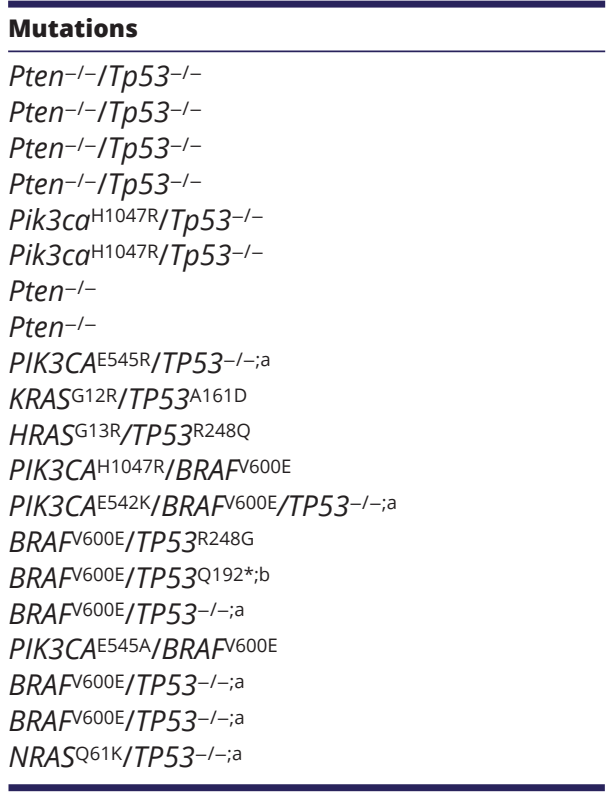

\begin{tabular}{l}
\hline Culture medium \\
\hline DMEM \\
DMEM \\
DMEM \\
DMEM \\
DMEM \\
DMEM \\
DMEM \\
DMEM \\
RPMI \\
DMEM \\
RPMI \\
RPMI \\
RPMI \\
RPMI \\
RPMI \\
RPMI \\
RPMI \\
RPMI \\
RPMI \\
DMEM
\end{tabular}

aTP53 mutant or deleted, however, no further details are available in published literature. bTP53 transcriptionally silenced.

(qRT-PCR) was conducted on a StepOne Plus apparatus using the Absolute Blue qPCR Rox Mix (Thermo Fisher Scientific) following the manufacturer's instructions. Each sample was run in triplicate and Akt2 and Actin were used to normalize the input RNA for mouse and human lines, respectively. Relative quantities were calculated using the $2^{(-\Delta \Delta \mathrm{Ct})}$ method. Primer sequences are available upon request.

\section{Cell cycle analysis}

For cell cycle analysis, cell lines were treated with DMSO (control), palbociclib $\left(\mathrm{EC}_{75}\right)$ and omipalisib $\left(\mathrm{EC}_{75}\right)$ for $72 \mathrm{~h}$. Cells were harvested by trypsin treatment and fixed in $75 \%$ ethanol in ice for 30 min. After treatment with RNase (Genentech/Roche) for $5 \mathrm{~min}$ at room temperature, cells were stained with propidium iodide (BioSure, Grass Valley, CA, USA) overnight, and DNA content was measured using a BD FACSCanto II system (BD Biosciences).

\section{Apoptosis analysis}

Cells were treated with DMSO (control), palbociclib $\left(\mathrm{EC}_{75}\right)$ and omipalisib $\left(\mathrm{EC}_{75}\right)$ for $72 \mathrm{~h}$. At the end of treatment, cells were harvested by trypsinization. The supernatant was also collected. Cells were stained with Annexin V FITC and propidium iodide (BD Biosciences) for $15 \mathrm{~min}$ at room temperature in darkness. Samples were analyzed by flow cytometry within $1 \mathrm{~h}$ using a BD FACSCanto II system (BD Biosciences). Flow cytometry analysis was performed on the FloJo platform.

\section{Colony formation assay}

For washout experiments, THJ16T cells were treated for $72 \mathrm{~h}$ with palbociclib $\left(\mathrm{EC}_{50}\right)$ and omipalisib $\left(\mathrm{EC}_{50}\right)$, alone or in combination. After pre-treatment, live cells were counted, seeded at 400 cells/well and cultured under routine conditions for 10 days. Medium was replaced as needed.

For continuous exposure experiments, 400 cells per well were seeded. Twelve hours after seeding, cells were treated as above. Medium and drugs were replaced every 3 days. Colonies were fixed with $0.1 \%$ methanol and stained with $0.05 \%$ crystal violet (Sigma-Aldrich).

\section{In vivo experiments}

NOD-scid IL2rynull (NSG) mice, aged 6- to 8-weeks old, from the Einstein Shared Facility in Stem Cell Research, were injected subcutaneously with $5 \times 10^{6}$ THJ16T cells. Equal number of males and females were used. When tumors reached a size of $100 \mathrm{~mm}^{3}$, mice were randomized to control, palbociclib, omipalisib and combination treatment groups. Palbociclib was dissolved in $50 \mathrm{mM} \mathrm{Na}$ lactate, $\mathrm{pH}$ 4.0. Omipalisib was dissolved in 40\% PEG300/16\% 2-hydroxypropyl- $\beta$-cyclodextrin. Both compounds were administered via oral gavage at (c) 2019 Society for Endocrinology Published by Bioscientifica Ltd. Printed in Great Britain 
$0.3 \mathrm{mg} / \mathrm{kg} / \mathrm{day}$ and $30 \mathrm{mg} / \mathrm{kg} / \mathrm{day}$, respectively. Palbociclib as single agent (first experiment) was used at $50 \mathrm{mg} / \mathrm{kg} /$ day. Tumor volume was calculated from twodimensional measurements using the equation: tumor volume $=\left(\right.$ length $\times$ width $\left.^{2}\right) \times 0.5$, every 2 days. Tumor weight was measured at the end of the experiment. Data were plotted and analyzed using GraphPad Prism. Growth rate was statistically analyzed comparing the growth rate of treated and control tumors as described by Hather et al. (2014).

All the animal studies were approved by the Einstein Institutional Animal Care and Use Committee.

\section{Immunohistochemistry}

Tissues were paraffin embedded and sectioned at $5 \mu \mathrm{m}$. To assess the proliferation status of the tumor cells, Ki67 staining was performed (Yeager et al. 2008).
Immunostaining of apoptotic cells was carried out using the TUNEL assay (Yeager et al. 2008).

\section{Results}

\section{CDK4/6 inhibition reduces ATC cell proliferation}

Combined analysis of published datasets from large-scale exome sequencing of ATC samples (Kunstman et al. 2015, Landa et al. 2016, Pozdeyev et al. 2018) reveals that the tumor suppressor gene $R B 1$ is mutated with an overall frequency lower than 6\% (Fig. 1A). Accordingly, Western blot analysis of several ATC cell lines showed detectable RB expression in all samples, except in T243 cells (Fig. 1B).

Thus, we hypothesized that this low mutation frequency might open a previously underappreciated therapeutic opportunity for ATC patients. In fact, we found that, although expressed, RB is phosphorylated and
A
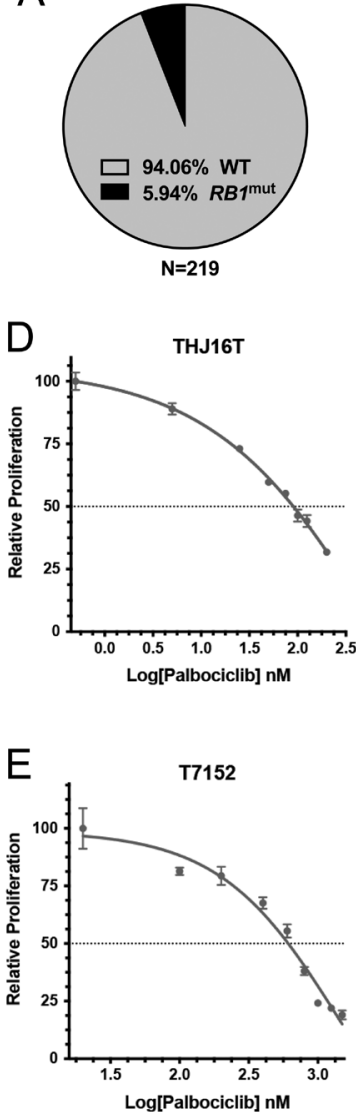
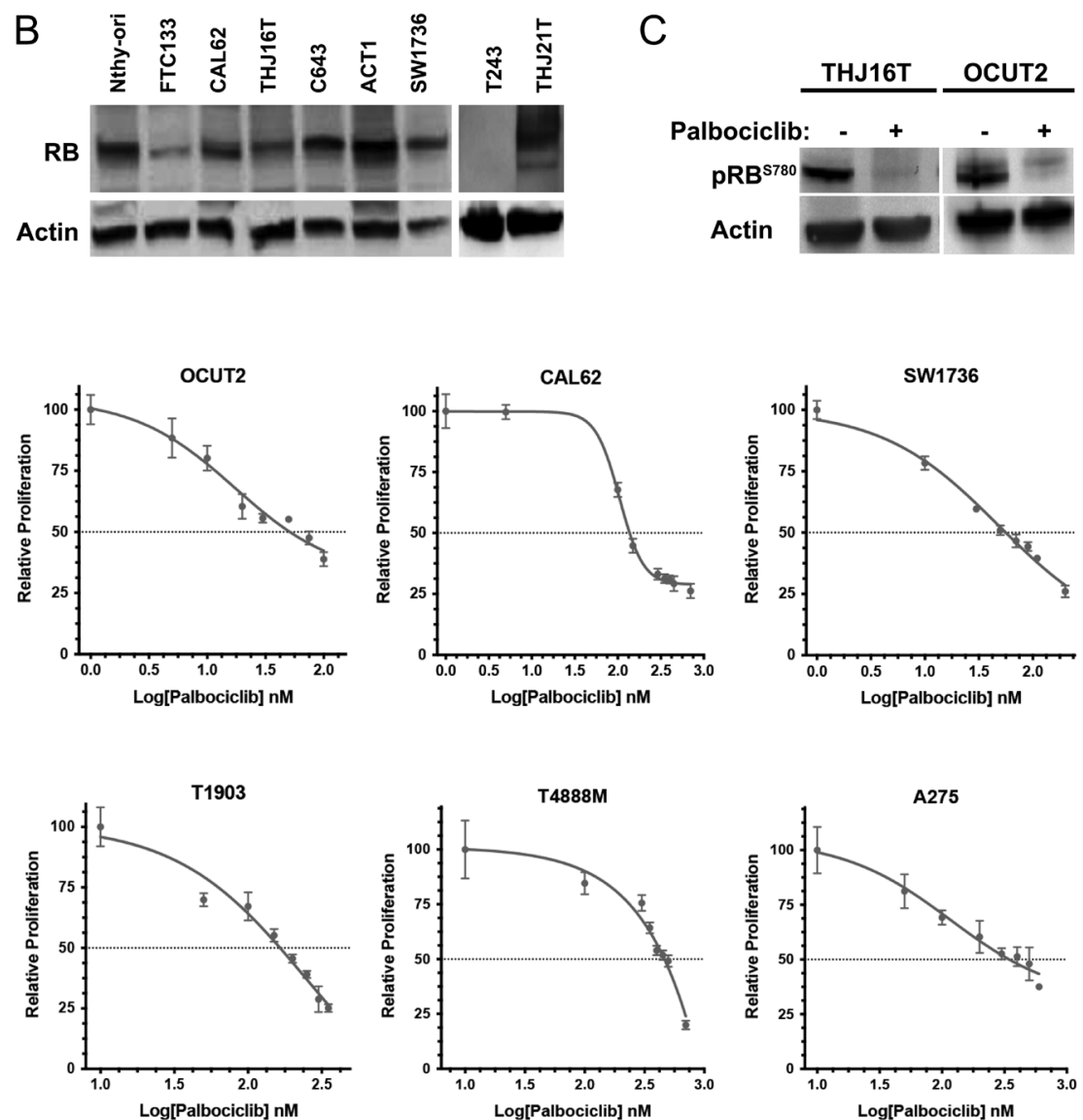

C
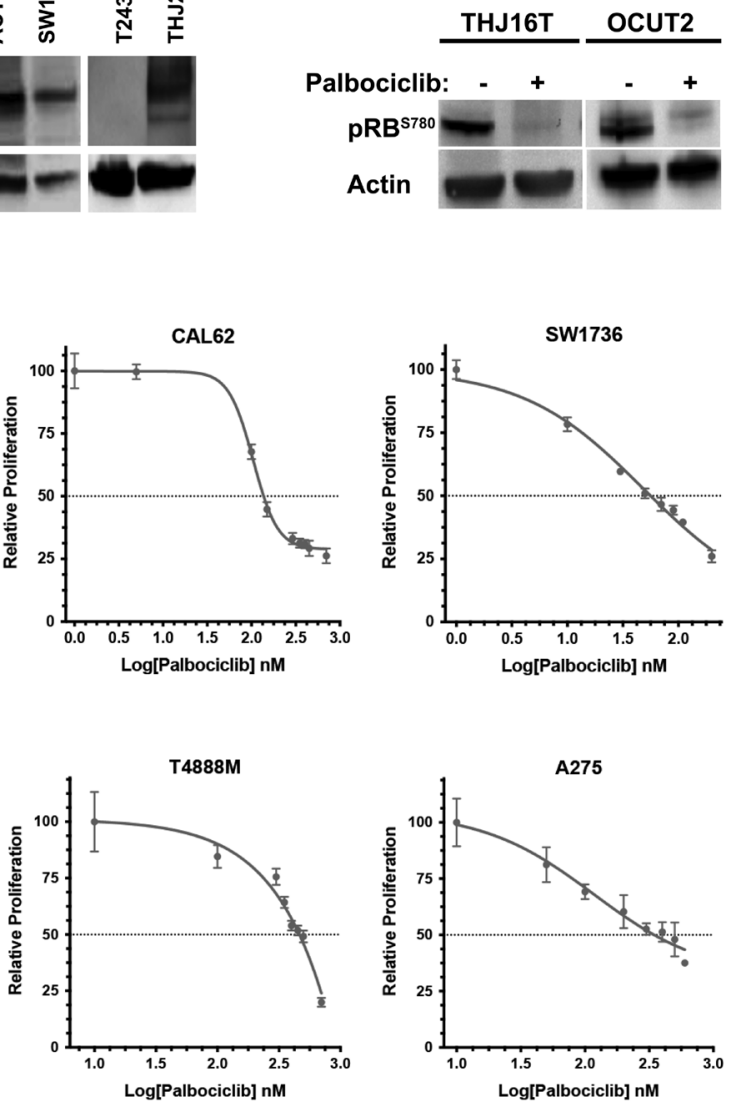

Figure 1

Palbociclib activity in ATC cell lines. (A) Prevalence of RB1 mutations in human ATC. (B) Western blot analysis of RB expression in human ATC cell lines. Nthy-ori (non-tumor, immortalized) and FTC133 (follicular thyroid carcinoma) are shown as controls. (C) Effect of $1 \mathrm{~h}$ treatment with $100 \mathrm{nM}$ palbociclib on RB phosphorylation in two representative ATC cell lines. (D and E) Dose/response analysis of palbociclib effect on the proliferation of human (D) and mouse (E) ATC cell lines. 
inactivated in all ATC cell lines, and that exposure to the CDK4/6 inhibitor, palbociclib (Fry et al. 2004), results in rapid dephosphorylation of RB (Fig. 1C).

We then proceeded to test the effect of CDK4/6 inhibition on the proliferation of a large panel of human and mouse ATC cell lines encompassing the whole spectrum of mutations observed in ATC patients (Table 1). Notably, preliminary experiments revealed that palbociclib treatment is not compatible with metabolic activity assays such as alamar blue, as it leads to a significant underestimation of palbociclib cell growthinhibitory activity. For this reason, we utilized direct cell counting after $72 \mathrm{~h}$ of treatment. Our data clearly show that palbociclib potently inhibits the proliferation of both human and mouse ATC cells (Fig. 1E and Supplementary Fig. 1, see section on supplementary data given at the end of this article).

The $\mathrm{EC}_{50}$ for palbociclib is between 20 and $90 \mathrm{nM}$ for human cell lines carrying activating mutations in $B R A F$ and/or PIK3CA, and between 140 and $340 \mathrm{nM}$ for cell lines with RAS activating mutations. T243, which does not express $\mathrm{RB}$, is completely insensitive even to micromolar doses of palbociclib, suggesting that RB expression is essential for the activity of this compound (Fig. 2A). Mouse cell lines were slightly less sensitive, with $\mathrm{EC}_{50} \mathrm{~S}$ between 130 and $620 \mathrm{nM}$.

We profiled the mRNA expression of $R B 1, C D K 4, C D K 6$ and $C D K N 2 A$, which have been shown to determine the sensitivity to CDK4/6 inhibitors (Supplementary Fig. 2A), and correlated the expression levels of these genes with the $\mathrm{EC}_{50}$ of each human cell line. p16/CDKN2A was undetectable in the majority of ATC cell lines, with the exception of T238 and T243. While no significant correlation was found between expression of CDK6 (or RB1) and cell lines' sensitivity to palbociclib (Supplementary Fig. 2B and C), we found a significant inverse correlation $(P=0.02)$ between $C D K 4$ expression and ATC sensitivity to palbociclib (Fig. 2B).

Flow cytometry analysis in two cell lines carrying PIK3CA-activating mutations showed that CDK4/6 inhibition leads to cell cycle arrest in G1 (Fig. 2C), while no significant induction of apoptosis was observed up to 96h after treatment (Fig. 2D).

Thus, palbociclib effectively induces growth arrest in ATC cells, and the identity of the driver genetic alteration has a limited effect on sensitivity to the drug.

\section{Rapid induction of resistance to CDK4/6 inhibition}

Based on these cell culture data, we used a xenograft model of ATC to test the effect of palbociclib treatment in vivo. THJ16T human ATC cells were implanted in NSG mice, and tumor-carrying mice were treated with vehicle or $50 \mathrm{mg} / \mathrm{kg}$ palbociclib for up to 4 weeks. Treatment with the inhibitor drastically reduced tumor growth for the first 2 weeks, after which a trend toward increased proliferation became evident (Fig. 3A). The same effect was also observed in cell culture. When THJ16T cells were treated
A

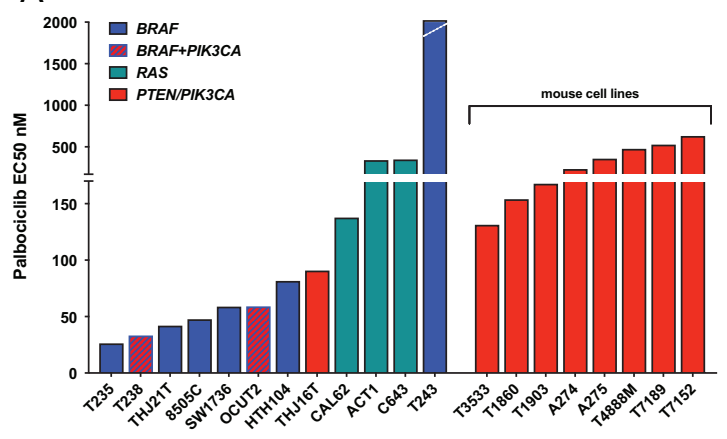

B

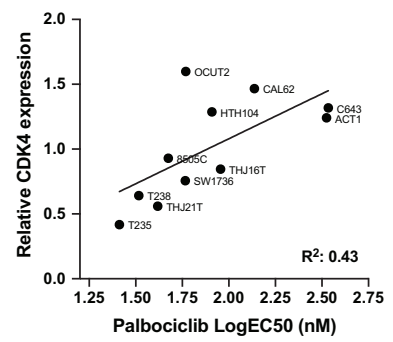

C

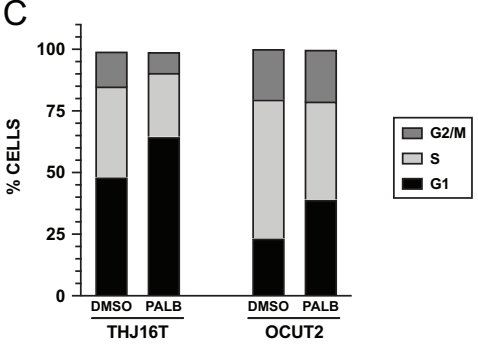

$\mathrm{D}$

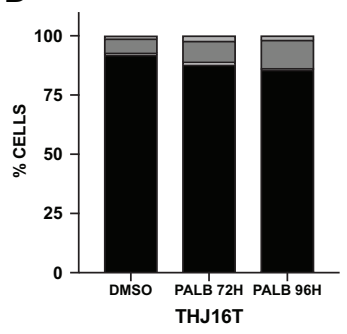

Figure 2

Palbociclib activity in ATC cell lines. (A) Calculated $E_{50}$ for the human and mouse ATC cell lines analyzed. (B) Correlation between mRNA expression of CDK4 and sensitivity to palbociclib in human ATC cell lines. (C) Cell cycle distribution of two human ATC cell lines after $72 \mathrm{~h}$ treatment with $120 \mathrm{nM}\left(\mathrm{EC}_{75}\right)$ palbociclib. (D) Apoptotic profile of THJ16T cell treated for 72 and $96 \mathrm{~h}$ with $120 \mathrm{nM}\left(\mathrm{EC}_{75}\right)$ palbociclib. AV, annexin V; PI, propidium iodide. 

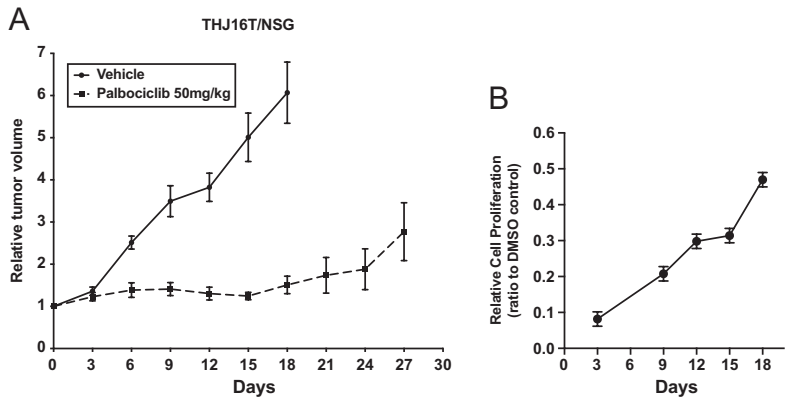

C

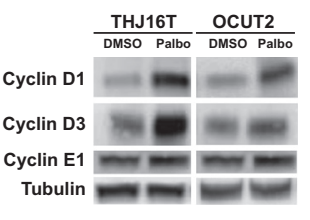

Figure 3

In vivo efficacy of palbociclib. (A) NSG mice carrying THJ16T xenografts were treated with vehicle or $50 \mathrm{mg} / \mathrm{kg} /$ day palbociclib. (B) Long-term analysis of THJ16T proliferation treated continuously with $250 \mathrm{nM}$ (EC90) palbociclib. (C) Western blot analysis of the expression of the indicated proteins in THJ16T and OCUT2 cells treated for $72 \mathrm{~h}$ with $120 \mathrm{nM}$ (EC75) palbociclib. with palbociclib at $\mathrm{EC}_{90}$, proliferation was abolished upon acute treatment, as expected. However, sequential counting and replating of these cells, maintaining the same drug concentration, revealed that cell proliferation resumed after a few days, and steadily increased over the next 2 weeks (Fig. 3B).

To understand the molecular basis for the reduced sensitivity to palbociclib treatment, we focused on cyclin $\mathrm{D}$ and cyclin E, whose upregulation has been previously associated with resistance to palbociclib.

Western blot analysis on cells treated for $72 \mathrm{~h}$ with palbociclib at $\mathrm{EC}_{75}$ revealed a significant increase in cyclin D1 and cyclin D3 protein levels upon treatment with palbociclib for $72 \mathrm{~h}$ (Fig. 3C), which suggests that D-type cyclins upregulation might be associated with the development of resistance to CDK4/6 inhibitors.

\section{PI3K/mTOR inhibition synergizes with palbociclib}

The notion that the PI3K pathway, and mTOR activity in particular, is involved in the control of cyclin D expression (Garcia-Morales et al. 2006, Averous et al. 2008) prompted us to test the effect of combining a dual PI3K/mTOR inhibitor, omipalisib (Knight et al. 2010), with palbociclib.

Dose-response experiments were conducted on a subset of mouse and human ATC cell lines, carrying mutations in the four most common oncogenic drivers found in ATC: PIK3CA, PIK3CA +BRAF, BRAF, RAS.

Combination of the two drugs exerted a potent growth suppressive effect in every cell line tested, even those not carrying mutations that directly activate the PI3K/mTOR signaling cascade (Fig. 4A). The CI calculated at $\mathrm{EC}_{75}$ and $\mathrm{EC}_{90}$ indicated that the combination was synergistic (three cell lines) or even strongly synergistic (three cell lines) (Fig. 4B).

We next tested the effect of combining palbociclib with a MEK inhibitor in those cell lines, among the ones tested above, that carry driver mutations (RAS, BRAF) activating MAPK signaling. The rationale was that also MAPK signaling can increase the expression level of cyclin D1
(Klein \& Assoian 2008). While MEK inhibition could still cooperate with CDK4/6 inhibition (Supplementary Fig. 3), the extent of synergy, as measured by the CI, was drastically lower than that obtained with PI3K/mTOR inhibition (Fig. 4B). Thus, even in cells that are driven by MAPK activation, PI3K/mTOR inhibition is superior in cooperating with CDK4/6 inhibition.

Flow cytometry experiments showed that cell cycle arrest was induced more potently in cells treated with combined palbociclib and omipalisib than in cells treated with each of the compounds alone (Fig. 4C). Once again, we did not detect apoptosis in cells treated with these compounds, alone or in combination (Fig. 4D), indicating that the growth suppressive effect is essentially mediated by cell cycle arrest in G0/G1.

To evaluate the long-term effect of combining the two inhibitors, we performed colony-forming assays using two different protocols. We first treated THJ16T cells with vehicle, palbociclib, omipalisib or a combination of the two drugs at their $\mathrm{EC}_{50}$ for 3 days, and then cells were counted and replated at low density for 10 days in medium devoid of drugs. The results clearly show that the growth suppressive effect exerted by these compounds is fully reversible, since drug washout restores normal proliferation rates, as indicated by the development of the same number of colonies, having the same size in all groups (Fig. 4E, top).

In a second approach, cells were directly plated at low density and maintained in the presence of compound(s) for the entire duration of the experiment. While palbociclib- and omipalisib-treated cells formed colonies with efficiency similar or slightly reduced compared to DMSO-treated cells, respectively, the combined treatment virtually abolished colony formation (Fig. 4E, bottom), indicating that inhibition of $\mathrm{PI} 3 \mathrm{~K} / \mathrm{mTOR}$ drastically impairs the development of resistance to palbociclib.

Surprisingly, we found that the combined treatment did not reduce cyclin D1 protein levels. However, the increase in cyclin D3 observed upon palbociclib treatment was completely abolished by the addition of omipalisib (c) 2019 Society for Endocrinology Published by Bioscientifica Ltd. Printed in Great Britain 

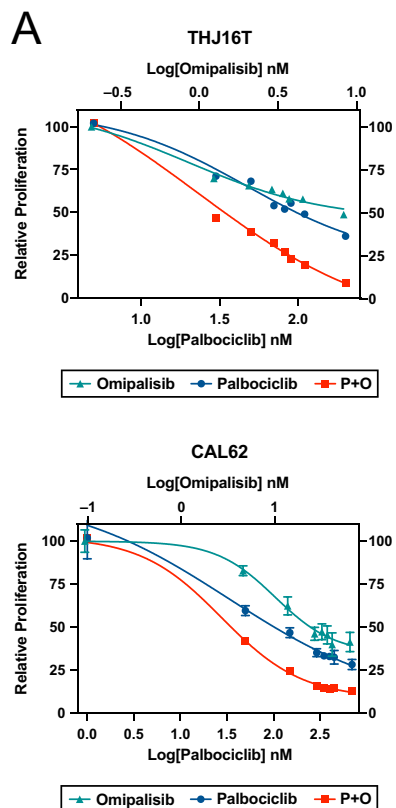
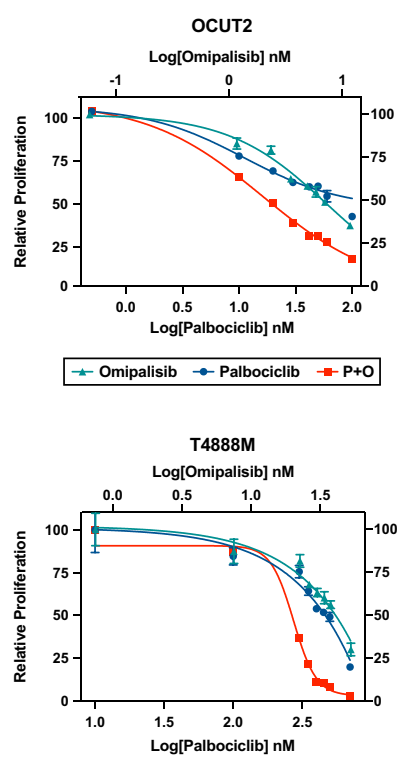

$\pitchfork$ Omipalisib $\rightarrow$ Palbociclib $\rightarrow \mathrm{P}+\mathrm{O}$
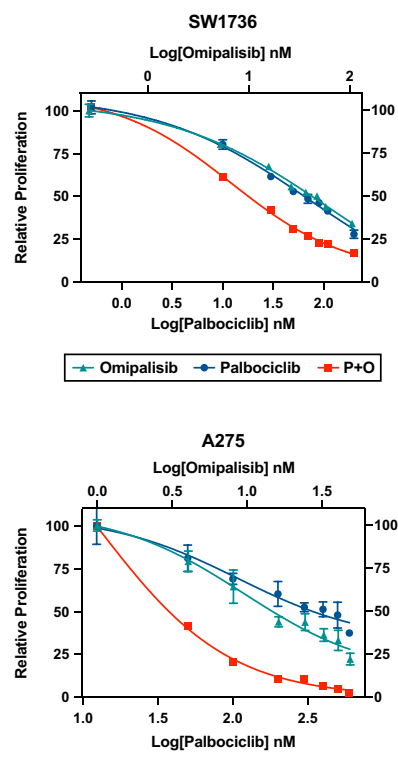

$\pitchfork$ Omipalisib $\rightarrow$ Palbociclib $\# \mathrm{P}+\mathrm{O}$

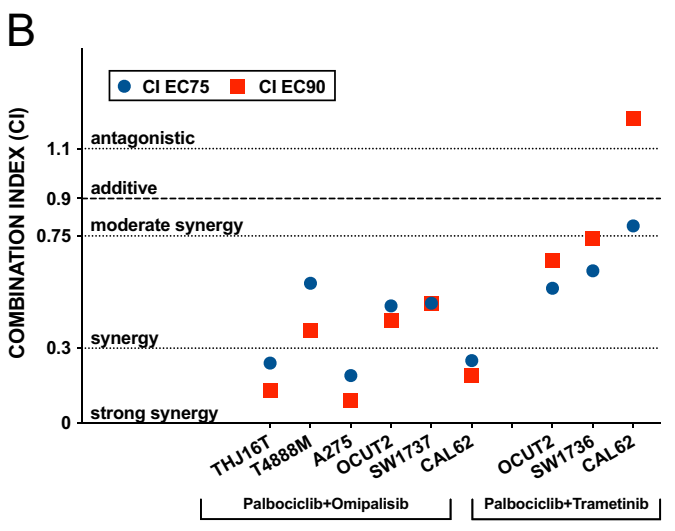

$E$
C
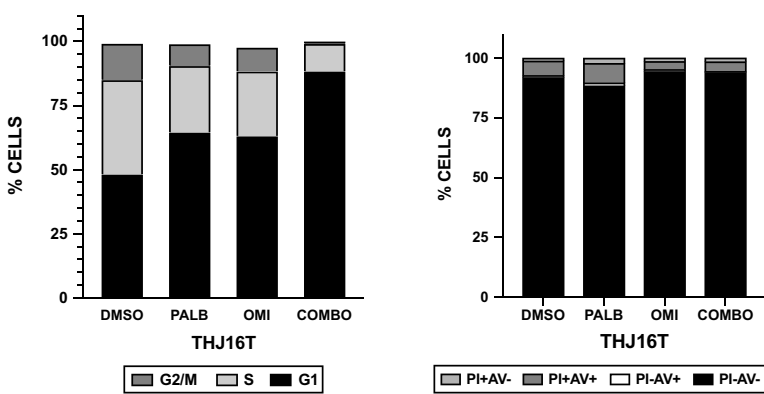

$\square$ Pl+AV- $\square$ Pl+AV+ $\square$ Pl-AV+
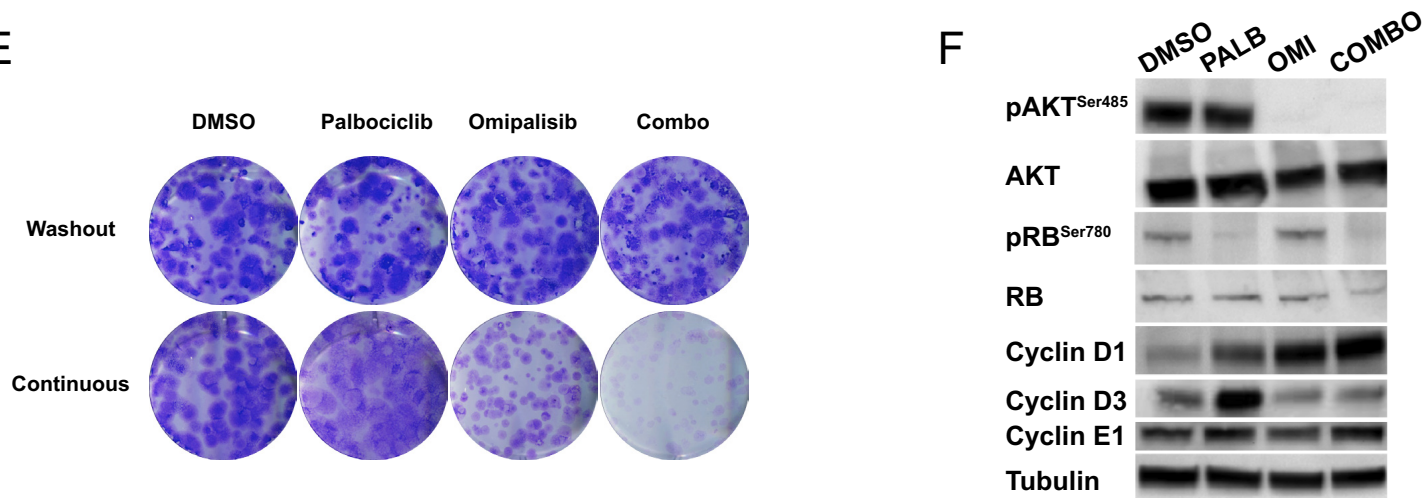

Figure 4

Synergy between palbociclib and omipalisib. (A) Dose/response plots showing the effect of single and combined treatment of ATC cells with palbociclib and omipalisib. (B) Plot of the combination index at $\mathrm{EC}_{75}$ and $\mathrm{EC}_{90}$ for $\mathrm{ATC}$ cell lines treated with palbociclib + omipalisib or trametinib. (C) Cell cycle distribution of THJ16T after $72 \mathrm{~h}$ treatment with $120 \mathrm{nM}\left(\mathrm{EC}_{75}\right.$ ) palbociclib and/or $55 \mathrm{nM}\left(\mathrm{EC}_{75}\right)$ omipalisib. (D) Apoptotic profile of THJ16T cell treated for $72 \mathrm{~h}$ with $120 \mathrm{nM}\left(E_{75}\right)$ palbociclib and/or $55 \mathrm{nM}\left(E_{75}\right)$ omipalisib. (E) Colony-forming assay of THJ16T cells treated with $80 \mathrm{nM}\left(E C_{50}\right)$ palbociclib and/or $8 \mathrm{nM}\left(\mathrm{EC}_{50}\right)$ omipalisib. $(\mathrm{F})$ Western blot analysis of the expression of the indicated proteins in THJ16T cells treated for $72 \mathrm{~h}$ with $120 \mathrm{nM}\left(\mathrm{EC}_{75}\right)$ palbociclib and/or $55 \mathrm{nM}\left(\mathrm{EC}_{75}\right)$ omipalisib. 
A

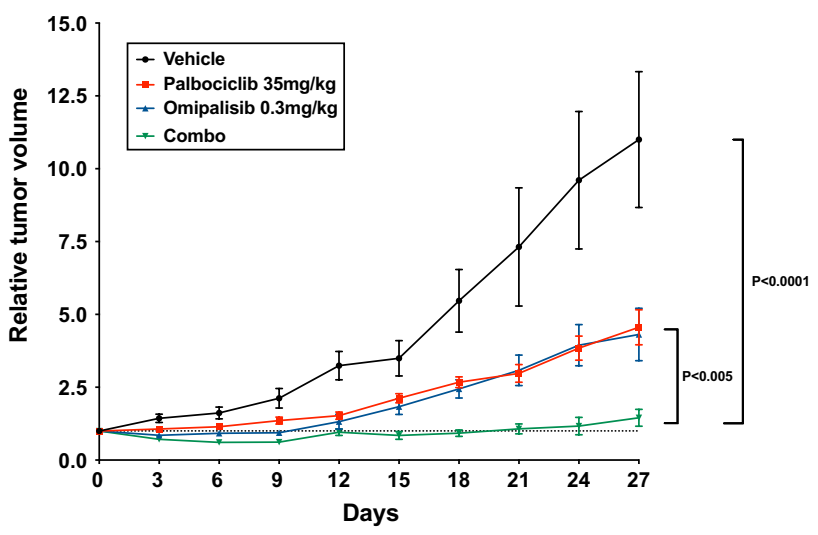

B

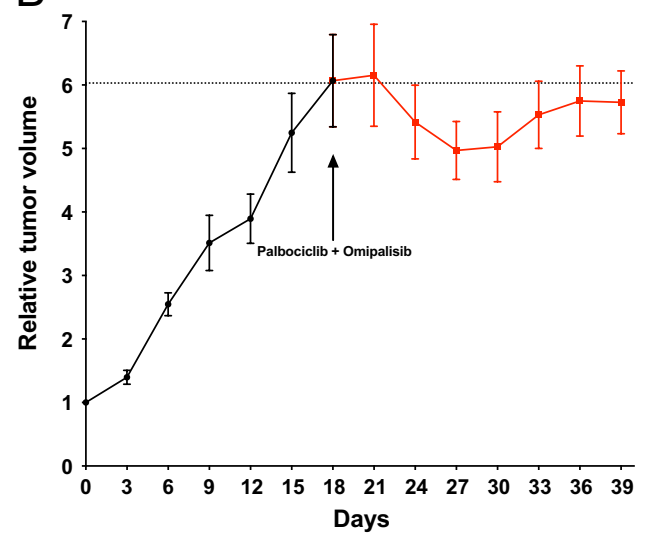

C

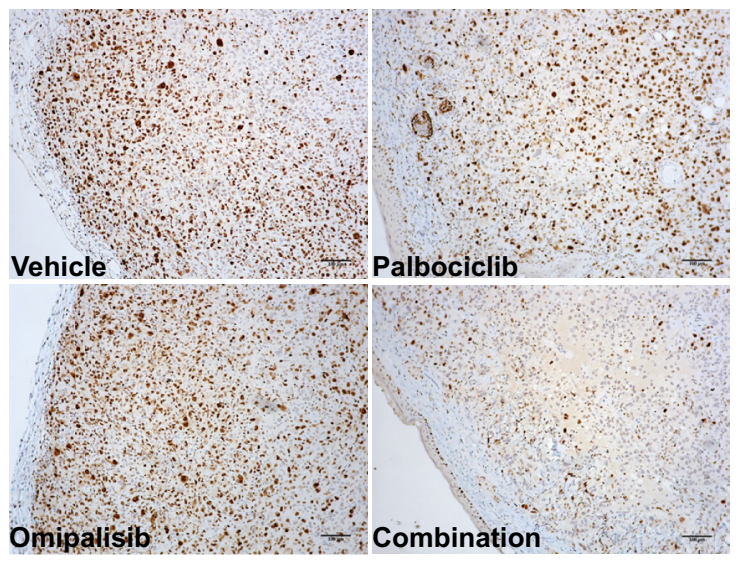

D

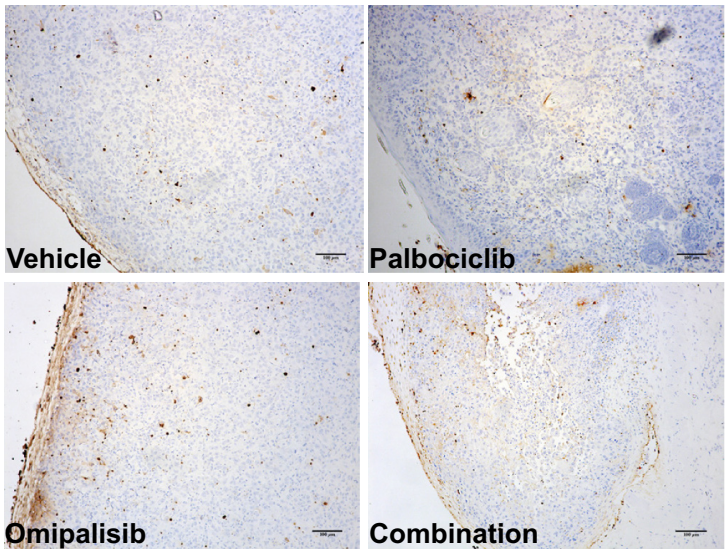

Figure 5

In vivo efficacy of combined palbociclib and omipalisib treatment. (A) NSG mice carrying THJ16T xenografts were treated with vehicle, $50 \mathrm{mg} / \mathrm{kg} / \mathrm{day}$ palbociclib, $0.3 \mathrm{mg} / \mathrm{kg} /$ day omipalisib or combination. (B) Mice carrying THJ16T xenografts were treated with combined drugs as in (A) starting when tumors had reached $500 \mathrm{~mm}^{3}$. (C) Immunohistochemical detection of Ki67 in sections from tumors treated as indicated. (D) TUNEL assay on sections from tumors treated as indicated. Bar: $100 \mu \mathrm{m}$.

(Fig. 4F). These data strongly suggest that the synergy observed combining CDK4/6 and PI3K/mTOR inhibitors is, at least in part, associated with the control of cyclin D3 levels.

\section{Combined therapy at low doses prevents tumor growth in vivo}

The strong synergy observed in cell culture models prompted us to test in vivo the effectiveness of combined CDK4/6 and PI3K/mTOR inhibition. We used again the THJ16T xenograft model in NSG mice. Preliminary experiments using $50 \mathrm{mg} / \mathrm{kg}$ palbociclib (same dose used in the previous experiment) combined with $1 \mathrm{mg} / \mathrm{kg}$ omipalisib (Knight et al. 2010) led however to toxic lethality. Based on the compelling synergy data, we reasoned that we could reduce the dosage to tolerable levels without losing tumor control effectiveness.

We found that NSG mice could tolerate a dose of $35 \mathrm{mg} / \mathrm{kg}$ of palbociclib combined with $0.3 \mathrm{mg} / \mathrm{kg}$ omipalisib without apparent toxic effects (Supplementary Fig. 4). We then treated cohorts of tumor-carrying mice with single drugs and combination for 4 weeks.

These lower doses of palbociclib and omipalisib were still able to significantly reduce tumor growth, compared to vehicle-treated control mice. Strikingly, we found that the combined treatment completely stopped tumor growth, demonstrating that the synergy observed in vitro was also maintained in an in vivo setting (Fig. 5A).

The in vivo effect of growth-inhibitory drugs can be misleading, since treatments are usually started when tumors are relatively small. ATC patients, instead,
C) 2019 Society for Endocrinology Published by Bioscientifica Ltd. Printed in Great Britain 
typically present with a rapid growing mass that has already invaded the nearby anatomical structures. To mimic this scenario, we let tumors grow until they reached a volume of about $500 \mathrm{~mm}^{3}$, and then started treatment.

Strikingly, we observed complete tumor growth inhibition for up to 3 weeks of follow-up (Fig. 5B). These data strongly suggest that combined CDK4/6 and PI3K/mTOR inhibition effectively inhibits the growth of even well-established tumors.

Finally, we used immunohistological detection of Ki67 to detect proliferating cells and TUNEL staining to detect apoptotic cells in sections of tumors from the four cohorts. In line with the cell culture data, we observed a dramatic suppression of cell proliferation in tumors treated with the drug combination, compared to both vehicle-treated and single drug-treated tumors (Fig. 5C). On the other hand, TUNEL staining did not detect any increase in the number of apoptotic cells in any of the treatment groups (Fig. 5D). Thus, also in vivo, robust inhibition of cell proliferation is the major mechanism of action of combined CDK4/6 and PI3K/mTOR inhibition.

\section{Discussion}

Therapeutic options for ATC are still extremely limited, despite recent durable response observed in over $60 \%$ of BRAF-mutant patients treated with a combination of dabrafenib and trametinib (Subbiah et al. 2018). The dismal prognosis associated with a diagnosis of ATC, including a median overall survival of only 9 months in the face of multimodal therapy (Prasongsook et al. 2017), underlines the urgent need for additional actionable targets that can offer prolonged survival to patients.

A characteristic feature of ATC, highlighted by recent large-scale analysis of the ATC genome, is the low mutation rate of the $R B 1$ tumor suppressor gene (Pozdeyev et al. 2018). This notion represented the rationale for our study, aimed at investigating the efficacy of palbociclib, a CDK4/6 inhibitor recently approved by the FDA for ER+ breast cancer (Walker et al. 2016), as a novel and effective therapeutic option for ATC.

Our cell culture data clearly demonstrate that CDK4/6 inhibition is very effective as a monotherapy in promoting cell cycle arrest, with EC50s in the low to mid-nanomolar range, in every ATC cell line that has a wild-type RB1 allele. Furthermore, palbociclib shows excellent tumor-inhibiting activity in a xenograft model of ATC. While one previous report had already analyzed the efficacy of a different CDK4/6 inhibitor, ribociclib, in two BRAF-mutant ATC cell lines (Lee et al. 2018), our study extends this analysis to a much larger panel of ATC lines, representative of all the common driver mutations found in human patients. Importantly, we did not find any difference in response to palbociclib between cells carrying activating mutations in BRAF or PIK3CA, while RAS mutant lines were somewhat less sensitive, which correlated with their higher expression levels of $C D K 4$. In fact, $C D K 4$ expression (but not that of $C D K 6$ or $R B 1$ ) was found to be inversely correlated to cells' sensitivity to palbociclib.

A key finding of our study was the rapid development of resistance to palbociclib in ATC cells. Cells grown in the presence of palbociclib resumed progressively faster proliferation within a week from treatment start, and xenograft tumors became significantly less responsive to palbociclib after 2 weeks of treatment. This pattern of resistance has been previously observed in practically all models analyzed (Pandey et al. 2018) and has been found associated most commonly with RB loss or mutation, cyclin D upregulation and cyclin E upregulation (HerreraAbreu et al. 2016, Jansen et al. 2017, Condorelli et al. 2018, Guarducci et al. 2018). Indeed, we found that cyclin D1 and D3, the main D-type cyclins in the thyroid, were overexpressed in cells treated with palbociclib. Given the established role of PI3K and mTOR in controlling cyclin D expression (Gupta et al. 2009), and previous reports showing the beneficial effects of PI3K or mTOR inhibition in preventing resistance to palbociclib (Herrera-Abreu et al. 2016, Asby et al. 2018, Chen et al. 2019), we decided to use a dual PI3K/mTOR inhibitor, omipalisib, in combination with palbociclib.

Our cell culture and in vivo data strongly support the role of PI3K/mTOR inhibition in potentiating the growth suppressive activity of palbociclib and in preventing the development of resistance. Two points merit particular attention: (i) this combination was effective even in cells without mutations activating PI3K, indicating that it could have broad clinical application; (ii) although a significant reduction of the commonly used doses $(30 \%$ for palbociclib, $70 \%$ for omipalisib) was operated to avoid toxicity, the combination therapy was extremely effective in preventing growth not only of developing tumors but also of larger, well-established lesions.

Although clinical development of omipalisib was halted because of suboptimal efficacy after we had started our experiments, these data represent a solid rationale to test novel dual inhibitors currently undergoing
(C) 2019 Society for Endocrinology Published by Bioscientifica Ltd. Printed in Great Britain 
clinical trials. In addition, future studies will need to assess the relative efficacy of selective PI3K vs mTOR inhibition in combination with palbociclib in ATC.

Several reports have described the development of senescence upon CDK4/6 inhibition (Chen \& Pan 2017, Vijayaraghavan et al. 2017). While this would be a desirable end point for palbociclib-based therapies, our data strongly suggest that continuous drug exposure is instead essential for the activity of this compound in ATC cells.

Another interesting result of our study is the specific downregulation of cyclin D3, but not cyclin D1, in the cells treated with the combination of CDK4/6 and $\mathrm{PI} 3 \mathrm{~K} / \mathrm{mTOR}$ inhibitors. The role of cyclin D3 in thyroid epithelial cell proliferation has already been established (Motti et al. 2003, Paternot et al. 2006), supporting the hypothesis that cyclin D3 is the key D-type cyclin that is involved in resistance to palbociclib in thyroid cancer. The unexpected upregulation of cyclin D1 upon PI3K/mTOR inhibition might be the effect of relief of a feedback and will need to be addressed in future studies.

Recent studies have provided evidence that, in addition to having a direct effect on the tumor, CDK4/6 inhibitors may influence cells in the tumor immune microenvironment, and specifically the infiltration of NK cells and the activation of T cells (Teo et al. 2017, Teh \& Aplin 2019). Future studies using our immunocompetent syngeneic models of ATC (Antico Arciuch et al. 2011, Champa \& Di Cristofano 2015) will address the relevance of this mechanism in ATC.

In summary, our findings suggest that combined CDK4/6 and PI3K/mTOR inhibition is synergistic in vitro and in vivo against a wide range of ATC cell lines and in a relevant preclinical xenograft model, and that it represents a novel approach for a lethal disease that warrants prompt evaluation in the clinical setting.

\section{Supplementary data}

This is linked to the online version of the paper at https://doi.org/10.1530/ ERC-19-0011.

\section{Declaration of interest}

Antonio Di Cristofano is an associate editor of Endocrine-Related Cancer. Antonio Di Cristofano was not involved in the review or editorial process for this paper, on which he is listed as an author. The other authors declare that there is no conflict of interest that could be perceived as prejudicing the impartiality of the research reported.

\section{Acknowledgements}

We are grateful to Pfizer for supplying palbociclib. We acknowledge the Animal Housing, Histopathology and Flow Cytometry Core Facilities of Albert Einstein College of Medicine, which are partially supported by the NIH Cancer Center Support Grant to the Albert Einstein Cancer Center (P30CA013330). Research reported in this publication was supported by NIH grants CA172012 and CA128943 to A Di Cristofano.

\section{References}

Ain KB, Egorin MJ \& Desimone PA 2000 Treatment of anaplastic thyroid carcinoma with paclitaxel: phase 2 trial using ninety-six-hour infusion. Collaborative Anaplastic Thyroid Cancer Health Intervention Trials (CATCHIT) Group. Thyroid 10 587-594. (https:// doi.org/10.1089/thy.2000.10.587)

Antico Arciuch VG, Russo MA, Dima M, Kang KS, Dasrath F, Liao XH, Refetoff S, Montagna C \& Di Cristofano A 2011 Thyrocyte-specific inactivation of p53 and Pten results in anaplastic thyroid carcinomas faithfully recapitulating human tumors. Oncotarget 2 1109-1126. (https://doi.org/10.18632/oncotarget.380)

Asby DJ, Killick-Cole CL, Boulter LJ, Singleton WG, Asby CA, Wyatt MJ, Barua NU, Bienemann AS \& Gill SS 2018 Combined use of CDK4/6 and mTOR inhibitors induce synergistic growth arrest of diffuse intrinsic pontine glioma cells via mutual downregulation of mTORC1 activity. Cancer Management and Research $103483-3500$. (https://doi.org/10.2147/CMAR.S167095)

Averous J, Fonseca BD \& Proud CG 2008 Regulation of cyclin D1 expression by mTORC1 signaling requires eukaryotic initiation factor 4E-binding protein 1. Oncogene 27 1106-1113. (https://doi. org/10.1038/sj.onc.1210715)

Champa D \& Di Cristofano A 2015 Modeling anaplastic thyroid carcinoma in the mouse. Hormones and Cancer 6 37-44. (https://doi. org/10.1007/s12672-014-0208-8)

Chen L \& Pan J 2017 Dual cyclin-dependent kinase 4/6 inhibition by PD-0332991 induces apoptosis and senescence in oesophageal squamous cell carcinoma cells. British Journal of Pharmacology $\mathbf{1 7 4}$ 2427-2443. (https://doi.org/10.1111/bph.13836)

Chen L, Yang G \& Dong H 2019 Everolimus reverses palbociclib resistance in ER+ human breast cancer cells by inhibiting phosphatidylinositol 3-kinase(PI3K)/Akt/mammalian target of rapamycin (mTOR) pathway. Medical Science Monitor 25 77-86. (https://doi.org/10.12659/MSM.912929)

Chou TC \& Talalay P 1984 Quantitative analysis of dose-effect relationships: the combined effects of multiple drugs or enzyme inhibitors. Advances in Enzyme Regulation 22 27-55. (https://doi. org/10.1016/0065-2571(84)90007-4)

Condorelli R, Spring L, O'shaughnessy J, Lacroix L, Bailleux C, Scott V, Dubois J, Nagy RJ, Lanman RB, Iafrate AJ, et al. 2018 Polyclonal RB1 mutations and acquired resistance to CDK 4/6 inhibitors in patients with metastatic breast cancer. Annals of Oncology 29 640-645. (https://doi.org/10.1093/annonc/mdx784)

Dima M, Miller KA, Antico-Arciuch VG \& Di Cristofano A 2011 Establishment and characterization of cell lines from a novel mouse model of poorly differentiated thyroid carcinoma: powerful tools for basic and preclinical research. Thyroid 21 1001-1007. (https://doi. org/10.1089/thy.2011.0030)

Fry DW, Harvey PJ, Keller PR, Elliott WL, Meade M, Trachet E, Albassam M, Zheng X, Leopold WR, Pryer NK, et al. 2004 Specific inhibition of cyclin-dependent kinase 4/6 by PD 0332991 and associated antitumor activity in human tumor xenografts. Molecular Cancer Therapeutics 3 1427-1438.

Garcia-Morales P, Hernando E, Carrasco-Garcia E, MenendezGutierrez MP, Saceda M \& Martinez-Lacaci I 2006 Cyclin D3 is (c) 2019 Society for Endocrinology Published by Bioscientifica Ltd. Printed in Great Britain 
down-regulated by rapamycin in HER-2-overexpressing breast cancer cells. Molecular Cancer Therapeutics 5 2172-2181. (https://doi. org/10.1158/1535-7163.MCT-05-0363)

Guarducci C, Bonechi M, Benelli M, Biagioni C, Boccalini G, Romagnoli D, Verardo R, Schiff R, Osborne CK, De Angelis C, et al. 2018 Cyclin $\mathrm{E} 1$ and $\mathrm{Rb}$ modulation as common events at time of resistance to palbociclib in hormone receptor-positive breast cancer. NPJ Breast Cancer 4 38. (https://doi.org/10.1038/s41523-018-0092-4)

Gupta M, Dillon SR, Ziesmer SC, Feldman AL, Witzig TE, Ansell SM, Cerhan JR \& Novak AJ 2009 A proliferation-inducing ligand mediates follicular lymphoma B-cell proliferation and cyclin D1 expression through phosphatidylinositol 3-kinase-regulated mammalian target of rapamycin activation. Blood 113 5206-5216. (https://doi.org/10.1182/blood-2008-09-179762)

Hather G, Liu R, Bandi S, Mettetal J, Manfredi M, Shyu WC, Donelan J \& Chakravarty A 2014 Growth rate analysis and efficient experimental design for tumor xenograft studies. Cancer Informatics 13 65-72. (https://doi.org/10.4137/CIN.S13974)

Herrera-Abreu MT, Palafox M, Asghar U, Rivas MA, Cutts RJ, GarciaMurillas I, Pearson A, Guzman M, Rodriguez O, Grueso J, et al. 2016 Early adaptation and acquired resistance to CDK4/6 inhibition in estrogen receptor-positive breast cancer. Cancer Research $\mathbf{7 6}$ 2301-2313. (https://doi.org/10.1158/0008-5472.CAN-15-0728)

Higashiyama T, Ito Y, Hirokawa M, Fukushima M, Uruno T, Miya A, Matsuzuka F \& Miyauchi A 2010 Induction chemotherapy with weekly paclitaxel administration for anaplastic thyroid carcinoma. Thyroid 20 7-14. (https://doi.org/10.1089/thy.2009.0115)

Iyer PC, Dadu R, Ferrarotto R, Busaidy NL, Habra MA, Zafereo M, Gross N, Hess KR, Gule-Monroe M, Williams MD, et al. 2018a Realworld experience with targeted therapy for the treatment of anaplastic thyroid carcinoma. Thyroid 28 79-87. (https://doi. org/10.1089/thy.2017.0285)

Iyer PC, Dadu R, Gule-Monroe M, Busaidy NL, Ferrarotto R, Habra MA, Zafereo M, Williams MD, Gunn GB, Grosu H, et al. 2018b Salvage pembrolizumab added to kinase inhibitor therapy for the treatment of anaplastic thyroid carcinoma. Journal for ImmunoTherapy of Cancer 6 68. (https://doi.org/10.1186/s40425-018-0378-y)

Jansen VM, Bhola NE, Bauer JA, Formisano L, Lee KM, Hutchinson KE, Witkiewicz AK, Moore PD, Estrada MV, Sánchez V, et al. 2017 Kinome-wide RNA interference screen reveals a role for PDK1 in acquired resistance to CDK4/6 inhibition in ER-positive breast cancer. Cancer Research 77 2488-2499. (https://doi.org/10.1158/00085472.CAN-16-2653)

Klein EA \& Assoian RK 2008 Transcriptional regulation of the cyclin D1 gene at a glance. Journal of Cell Science 121 3853-3857. (https://doi. org/10.1242/jcs.039131)

Knight SD, Adams ND, Burgess JL, Chaudhari AM, Darcy MG, Donatelli CA, Luengo JI, Newlander KA, Parrish CA, Ridgers LH, et al. 2010 Discovery of GSK2126458, a highly potent inhibitor of PI3K and the mammalian target of rapamycin. ACS Medicinal Chemistry Letters 1 39-43. (https://doi.org/10.1021/ml900028r)

Kunstman JW, Juhlin CC, Goh G, Brown TC, Stenman A, Healy JM, Rubinstein JC, Choi M, Kiss N, Nelson-Williams C, et al. 2015 Characterization of the mutational landscape of anaplastic thyroid cancer via whole-exome sequencing. Human Molecular Genetics 24 2318-2329. (https://doi.org/10.1093/hmg/ddu749)

Landa I, Ibrahimpasic T, Boucai L, Sinha R, Knauf JA, Shah RH, Dogan S, Ricarte-Filho JC, Krishnamoorthy GP, Xu B, et al. 2016 Genomic and transcriptomic hallmarks of poorly differentiated and anaplastic thyroid cancers. Journal of Clinical Investigation 126 1052-1066. (https://doi.org/10.1172/JCI85271)

Lee HJ, Lee WK, Kang CW, Ku CR, Cho YH \& Lee EJ 2018 A selective cyclin-dependent kinase 4, 6 dual inhibitor, Ribociclib (LEE011) inhibits cell proliferation and induces apoptosis in aggressive thyroid cancer. Cancer Letters 417 131-140. (https://doi.org/10.1016/j. canlet.2017.12.037)

Motti ML, Boccia A, Belletti B, Bruni P, Troncone G, Cito L, Monaco M, Chiappetta G, Baldassarre G, Palombini L, et al. 2003 Critical role of cyclin D3 in TSH-dependent growth of thyrocytes and in hyperproliferative diseases of the thyroid gland. Oncogene 22 7576-7586. (https://doi.org/10.1038/sj.onc.1207055)

O'Leary B, Cutts RJ, Liu Y, Hrebien S, Huang X, Fenwick K, Andre F, Loibl S, Loi S, Garcia-Murillas I, et al. 2018 The genetic landscape and clonal evolution of breast cancer resistance to palbociclib plus fulvestrant in the PALOMA-3 trial. Cancer Discovery 8 1390-1403. (https://doi.org/10.1158/2159-8290.CD-18-0264)

Pandey K, An HJ, Kim SK, Lee SA, Kim S, Lim SM, Kim GM, Sohn J \& Moon YW 2018 Molecular mechanisms of resistance to CDK4/6 inhibitors in breast cancer: a review. International Journal of Cancer [epub]. (https://doi.org/10.1002/ijc.32020)

Patel KN \& Shaha AR 2006 Poorly differentiated and anaplastic thyroid cancer. Cancer Control 13 119-128. (https://doi. org/10.1177/107327480601300206)

Paternot S, Dumont JE \& Roger PP 2006 Differential utilization of cyclin $\mathrm{D} 1$ and cyclin D3 in the distinct mitogenic stimulations by growth factors and TSH of human thyrocytes in primary culture. Molecular Endocrinology 20 3279-3292. (https://doi.org/10.1210/me.2005-0515)

Pozdeyev N, Gay LM, Sokol ES, Hartmaier R, Deaver KE, Davis S, French JD, Borre PV, Labarbera DV, Tan AC, et al. 2018 Genetic analysis of 779 advanced differentiated and anaplastic thyroid cancers. Clinical Cancer Research 24 3059-3068. (https://doi. org/10.1158/1078-0432.CCR-18-0373)

Prasongsook N, Kumar A, Chintakuntlawar AV, Foote RL, Kasperbauer J, Molina J, Garces Y, Ma D, Wittich MAN, Rubin J, et al. 2017 Survival in response to multimodal therapy in anaplastic thyroid cancer. Journal of Clinical Endocrinology and Metabolism 102 4506-4514. (https://doi.org/10.1210/jc.2017-01180)

Saini S, Tulla K, Maker AV, Burman KD \& Prabhakar BS 2018 Therapeutic advances in anaplastic thyroid cancer: a current perspective. Molecular Cancer 17 154. (https://doi.org/10.1186/s12943-018-0903-0)

Sherman EJ, Lim SH, Ho AL, Ghossein RA, Fury MG, Shaha AR, Rivera M, Lin O, Wolden S, Lee NY, et al. 2011 Concurrent doxorubicin and radiotherapy for anaplastic thyroid cancer: a critical re-evaluation including uniform pathologic review. Radiotherapy and Oncology 101 425-430. (https://doi.org/10.1016/j. radonc.2011.09.004)

Sherr CJ 2000 The Pezcoller lecture: cancer cell cycles revisited. Cancer Research 60 3689-3695.

Smallridge RC 2012 Approach to the patient with anaplastic thyroid carcinoma. Journal of Clinical Endocrinology and Metabolism 97 2566-2572. (https://doi.org/10.1210/jc.2012-1314)

Subbiah V, Kreitman RJ, Wainberg ZA, Cho JY, Schellens JHM, Soria JC, Wen PY, Zielinski C, Cabanillas ME, Urbanowitz G, et al. 2018 Dabrafenib and trametinib treatment in patients with locally advanced or metastatic BRAF V600-mutant anaplastic thyroid cancer. Journal of Clinical Oncology 36 7-13. (https://doi.org/10.1200/ JCO.2017.73.6785)

Teh JLF \& Aplin AE 2019 Arrested developments: CDK4/6 inhibitor resistance and alterations in the tumor immune microenvironment. Clinical Cancer Research 25 921-927.

Teo ZL, Versaci S, Dushyanthen S, Caramia F, Savas P, Mintoff CP, Zethoven M, Virassamy B, Luen SJ, Mcarthur GA, et al. 2017 Combined CDK4/6 and PI3Kalpha inhibition is synergistic and immunogenic in triple-negative breast cancer. Cancer Research $\mathbf{7 7}$ 6340-6352. (https://doi.org/10.1158/0008-5472.CAN-17-2210)

Vijayaraghavan S, Karakas C, Doostan I, Chen X, Bui T, Yi M, Raghavendra AS, Zhao Y, Bashour SI, Ibrahim NK, et al. 2017 CDK4/6 and autophagy inhibitors synergistically induce senescence https://erc.bioscientifica.com

https://doi.org/10.1530/ERC-19-0011 (c) 2019 Society for Endocrinology Published by Bioscientifica Ltd. Printed in Great Britain 
in $\mathrm{Rb}$ positive cytoplasmic cyclin E negative cancers. Nature Communications 8 15916. (https://doi.org/10.1038/ncomms15916)

Walker AJ, Wedam S, Amiri-Kordestani L, Bloomquist E, Tang S, Sridhara R, Chen W, Palmby TR, Fourie Zirkelbach J, Fu W, et al. 2016 FDA approval of palbociclib in combination with fulvestrant for the treatment of hormone receptor-positive, HER2-negative metastatic breast cancer. Clinical Cancer Research 22 4968-4972. (https://doi.org/10.1158/1078-0432.CCR-16-0493)

Yeager N, Brewer C, Cai KQ, Xu XX \& Di Cristofano A 2008 Mammalian target of rapamycin is the key effector of phosphatidylinositol-3-OHinitiated proliferative signals in the thyroid follicular epithelium. Cancer Research 68 444-449. (https://doi.org/10.1158/0008-5472.CAN-07-3030)

Received in final form 28 January 2019

Accepted 30 January 2019

Accepted Preprint published online 30 January 2019
C) 2019 Society for Endocrinology Published by Bioscientifica Ltd. Printed in Great Britain 